\title{
Preparation and characterization of alumina-supported iron nanoparticles and its application for the removal of aqueous $\mathrm{Cu}^{2+}$ ions
}

\author{
D. Karabelli a, S. Ünal ${ }^{\text {a }}$, T. Shahwan ${ }^{\mathrm{a}, \mathrm{b}, *}$, A.E. Eroğlu ${ }^{\mathrm{a}}$ \\ a Department of Chemistry, Izmir Institute of Technology, Urla 35430, Izmir, Turkey \\ ${ }^{\mathrm{b}}$ Department of Chemistry, Birzeit University, Ramallah, West Bank, Palestine
}

\section{A R T I C L E I N F O}

\section{Article history:}

Received 23 November 2010

Received in revised form

29 December 2010

Accepted 4 January 2011

\section{Keywords:}

Uptake

Iron nanoparticles

Alumina

$\mathrm{Cu}^{2+}$

\begin{abstract}
A B S T R A C T
A composite sorbent of iron nanoparticles and alumina (Al-nZVI) was prepared and applied in the removal of $\mathrm{Cu}^{2+}$ ions from aqueous solutions. Alumina was introduced in a solution of $\mathrm{Fe}^{2+}$ ions, which were then reduced to metallic iron nanoparticles using borohydride ions. The characterization results showed that iron nanoparticles were partially dispersed on alumina surface, with their diameter being in the range $10-80 \mathrm{~nm}$. The uptake experiments were performed at initial $\mathrm{Cu}^{2+}$ concentrations ranging from 10.0 to $500.0 \mathrm{mg} / \mathrm{L}$. The experiments investigated the effects of initial concentration, contact time, and repetitive usage of the Al-nZVI on the extent of removal of $\mathrm{Cu}^{2+}$ ions. The composite sorbent demonstrated fast uptake, and its fixation capacity was $1.50 \mathrm{mmol} / \mathrm{g}(95.3 \mathrm{mg} / \mathrm{g})$, which is well above that of pure alumina (0.32 mmol/g; $20.3 \mathrm{mg} / \mathrm{g})$.
\end{abstract}

(C) 2011 Elsevier B.V. All rights reserved.

\section{Introduction}

Copper ions are essential for the living organisms at trace level, but high dosage intake can cause detrimental health effects. Copper is one of the most common pollutants in industrial effluents, e.g. waste waters of electro-plating, metal-finishing, and paint industries [1]. Due to its potential toxicity, different types of adsorbents have been tested and proposed for the removal of aqueous $\mathrm{Cu}^{2+}$ ions [e.g. [2-10]].

Recently, iron nanoparticles and a composite sorbent of kaolinite-iron nanoparticles were reported by our group as effective sorbents for aqueous $\mathrm{Cu}^{2+}$ ions $[11,12]$. In both studies, the fixation of $\mathrm{Cu}^{2+}$ ions was shown to take place mainly via a redox mechanism that leads to the formation of metallic copper, $\mathrm{Cu}^{0}$, and cuprite, $\mathrm{Cu}_{2} \mathrm{O}$. The main factors behind the effectiveness of iron nanoparticles in the fixation of copper derive from the high surface/volume ratio of the nanoparticles, and the relatively high difference in standard reduction potential between $\mathrm{Fe}^{2+}(=-0.44 \mathrm{~V}, 298 \mathrm{~K})$ and $\mathrm{Cu}^{2+}(=+0.34 \mathrm{~V}$, $298 \mathrm{~K})$.

Due to their strong magnetic moments, iron nanoparticles are known to exist as aggregates the size of which can amountto

\footnotetext{
* Corresponding author at: Department of Chemistry, Birzeit University, Ramallah, West Bank, Palestine.

E-mail addresses: talalshahwan@iyte.edu.tr, tshahwan@birzeit.edu (T. Shahwan).
}

several micrometers. In a recent study, we have shown that this aggregation is enhanced further in aqueous media, where aggregates that are tens of micrometers in size can form [13]. The tendency to aggregation results in rapid sedimentation and consequently limited mobility of the nanoparticles in the aquatic media. Based on a field study, it was reported that iron nanoparticles migrate to only a few inches/a few feet inside groundwater [14].

The stability of iron nanoparticles against aggregation can be improved by imparting electrostatic repulsion and/or by applying organic surfactants that result in steric stabilization [15]. Alternatively, synthesizing iron nanoparticles in the presence of a solid matrix can lead to decreasing the tendency of aggregation of iron nanoparticles. This was verified by applying kaolinite and bentonite as solid materials in our previous studies $[12,16]$. Alumina, being a widely available natural inorganic solid, that is stable over a wide range of geochemical conditions, could therefore be appropriate for this purpose.

In this study, iron nanoparticles were prepared in the presence of alumina. The composite adsorbent $(\mathrm{Al}-\mathrm{nZVI})$ was then used in the removal of aqueous $\mathrm{Cu}^{2+}$ ions under different experimental conditions. Parallel experiments were also performed using pure alumina for the sake of comparison. The adsorbents were characterized using scanning electron microscopy/energy dispersive $\mathrm{X}$-ray analysis (SEM/EDX), high-resolution transmission electron microscopy (HR-TEM), and X-ray diffraction (XRD), and X-ray photoelectron spectroscopy (XPS). The concentration of $\mathrm{Cu}^{2+}$ in aqueous solutions was determined using flame-atomic absorption spectroscopy (FAAS). 

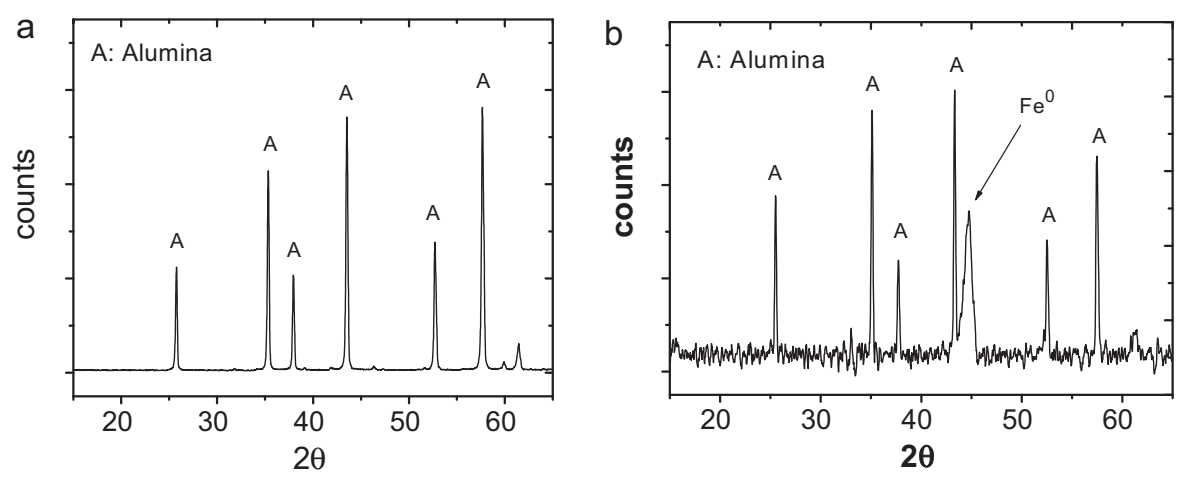

Fig. 1. XRD patterns of: (a) alumina, (b) Al-nZVI.

\section{Experimental}

\subsection{Preparation of $A l-n Z V I$}

The composite adsorbent (Al-nZVI) was prepared with a $\mathrm{Fe}^{2+}$ :alumina ratio of $1: 1$ mass proportion. This was realized by dissolving $5.34 \mathrm{~g}$ of $\mathrm{FeCl}_{2} \cdot 4 \mathrm{H}_{2} \mathrm{O}$ in $25.0 \mathrm{~mL}$ of an ethanol-water solution $(20.0 \mathrm{~mL}$ ethanol $+5.0 \mathrm{~mL}$ water). Subsequently, $1.5 \mathrm{~g}$ of alumina powder was added to the solution and mixed in an ultrasonic shaker for $20 \mathrm{~min}$. The $\mathrm{NaBH}_{4}$ solution was prepared separately by dissolving $2.54 \mathrm{~g}$ of the material in $70.0 \mathrm{~mL}$ of distilled water. The borohydride solution was added to the iron-alumina mixture under continuous stirring. After the addition of borohydride solution, the mixture was mixed for another $20 \mathrm{~min}$. Vacuum filtration was used to separate the solid from the solution, and the obtained Al-nZVI was washed 3 times with absolute ethanol. The sample was finally dried in oven at $50^{\circ} \mathrm{C}$, and stored in desiccators under ambient conditions.

\subsection{Uptake experiments}

A stock $\mathrm{Cu}^{2+}$ solution $(1000.0 \mathrm{mg} / \mathrm{L})$ was prepared by dissolving the proper quantity of $\mathrm{Cu}\left(\mathrm{NO}_{3}\right)_{2} \cdot 5 / 2 \mathrm{H}_{2} \mathrm{O}$ salt in ultra pure water $(18 \mathrm{M} \Omega$ ). The solutions used in the uptake experiments (namely 10.0, 50.0, 100.0, 200.0, and $500.0 \mathrm{mg} / \mathrm{L}$ ) were then prepared by serial dilution.

The effect of time on the uptake process was studied at the initial $\mathrm{Cu}^{2+}$ concentration of 100.0 and $500.0 \mathrm{mg} / \mathrm{L}$, by mixing $50.0 \mathrm{~mL}$ portions of $\mathrm{Cu}^{2+}$ solution with $0.050 \mathrm{~g}$ of the composite sorbent. The mixtures were shaken in a water bath for time periods ranging from $1 \mathrm{~min}$ up to $24 \mathrm{~h}$. The supernatants were separated from the solid powder using centrifugation followed by filtration. The effect of concentration on $\mathrm{Cu}^{2+}$ uptake was studied by mixing $50.0 \mathrm{~mL}$ portions of $10.0,50.0,100.0,200.0$, and $500.0 \mathrm{mg} / \mathrm{L} \mathrm{Cu}^{2+}$ solution with $0.050 \mathrm{~g}$ samples of the sorbent for $4 \mathrm{~h}$. The reusability of the sorbent was tested by mixing $50.0 \mathrm{~mL}$ portions of 10.0 or $100.0 \mathrm{mg} / \mathrm{L}$ of $\mathrm{Cu}^{2+}$ solution with $0.050 \mathrm{~g}$ nZVI and shaking for $1 \mathrm{~h}$. The mixture was then centrifuged and the solid sample was re-exposed to another $50 \mathrm{~mL}$ portion of fresh $\mathrm{Cu}^{2+}$ solution. The process was repeated for five successive trials. The effect of $\mathrm{pH}$ on the uptake of $\mathrm{Cu}^{2+}$ was examined at the starting $\mathrm{pH}$ values of 3.0, 5.0, 7.0, 9.0, and 11.0 and the applied initial $\mathrm{Cu}^{2+}$ concentration was $50.0 \mathrm{mg} / \mathrm{L}$. In each experiment, $50.0 \mathrm{~mL}$ portions of $\mathrm{Cu}^{2+}$ solution were mixed with $0.050 \mathrm{~g} \mathrm{Al-nZVI}$ and were shaken for $4 \mathrm{~h}$.

The $\mathrm{pH}$ of the solution media was measured before mixing $\mathrm{Cu}^{2+}$ solutions with the sorbent samples, and at the end of the experiments. The $\mathrm{pH}$ of the $\mathrm{Cu}^{2+}$ solutions before mixing with the adsorbents was in the range 6.42-4.67 depending on the initial concentration, the higher the concentration the lower was the $\mathrm{pH}$. At the end of uptake experiments, the measured $\mathrm{pH}$ ranged between 5.58 and 4.91. Based on chemical speciation analysis performed using visual MINTEQ software [11], within the given pH conditions, the divalent ionic form is the dominant form of copper.

In all cases, the mixtures were contained in Falcon tubes. The liquid phase was analyzed by atomic absorption spectroscopy (AAS) using a Thermo Elemental SOLAAR M6 Series spectrometer with air-acetylene flame. The solid samples were characterized using XRD, HR-TEM, and SEM/EDX. A Philips X'Pert Pro instrument was used for the XRD analysis. The instrument is located at the Center of Materials Research at Izmir Institute of Technology. The source consisted of $\mathrm{Cu} K \alpha$ radiation $(\lambda=1.54 \AA)$. Each sample was scanned within the $2 \theta$ range of $20-70^{\circ}$. HR-TEM analysis was performed using a Tecnai F20 instrument located at Max Planck Institute for polymer research. The instrument was operated at $200 \mathrm{kV}$ acceleration voltage. Prior to analysis, the sample was dispersed in ethanol using an ultrasonic bath. Subsequently, a drop of the dispersion was applied to a holey carbon TEM support grid, and excess solution was blotted off by a filter paper. SEM/EDX analysis was carried out using a Philips XL-30S FEG type instrument located at the Center of Materials Research at İzmir Institute of Technology. The solid samples were first sprinkled onto adhesive carbon tapes supported on metallic disks. Images of the sample surfaces were recorded at different magnifications. The XPS analysis was performed using a Thermo VG Scientific X-ray photoelectron spectrometer (Al-K $\alpha$ $1486.6 \mathrm{eV}$ source) located at the Interface Analysis Centre at Bristol University. The samples were mounted in Al holders and analyzed under high vacuum $\left(<1 \times 10^{-7} \mathrm{mbar}\right)$. Data analysis was carried out using Pisces software.

\section{Results and discussion}

\subsection{Characterization results for Al-nZVI}

Alumina used in this work was of a natural origin from Turkey. According to the obtained XRD reflections, the material appeared to be of $\alpha-\mathrm{Al}_{2} \mathrm{O}_{3}$ type. EDX elemental analysis showed that the material is free of detectable elemental impurities. The XRD patterns of alumina and $\mathrm{Al}-\mathrm{nZVI}$ are given in Fig. $1 \mathrm{a}$ and b. As Fig. $1 \mathrm{~b}$ shows, iron in $\mathrm{Al}-\mathrm{nZVI}$ is in its $\mathrm{Fe}^{0}$ state as indicated by the primary reflection at $2 \theta=44.9^{\circ}$. No signal of iron oxide is observed in the XRD pattern which indicates that any oxidation was below the detection limit of XRD. Moreover, successive XRD analysis showed that no significant oxidation took place in Al-nZVI samples stored under normal conditions for more than a month.

Typical SEM images of alumina and Al-nZVI composite are given in Fig. 2. Alumina appears to be composed of flakes that are about $1 \mu \mathrm{m}$ or less in size (Fig. 2a). The Al-nZVI composite is seen to be heterogeneous. As Fig. 2b shows, part of the iron nanoparticles 

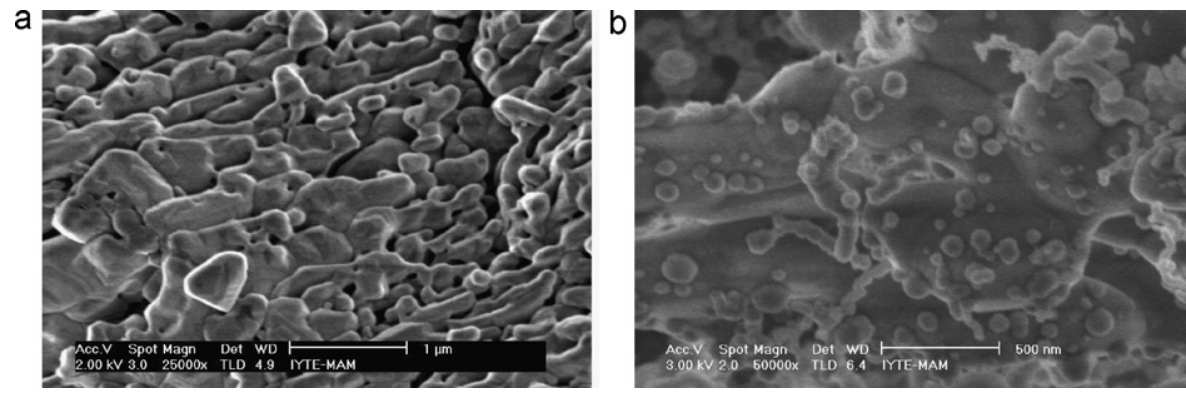

Fig. 2. Typical SEM images of: (a) alumina, (b) Al-nZVI.

appears to exist in dispersed form on the surface of alumina, while another part exists in its distinct chain-like structure that resembles that of pure nZVI. The identity of the dispersed nanoparticles was confirmed using multiple EDX spot analysis. The particle size of the iron particles is estimated to be within the range $10-80 \mathrm{~nm}$.

TEM images of Al-nZVI, shown in Fig. 3, support the SEM characterization results and show also that iron nanoparticles possess its characteristic core-shell structure. The core is dominated by zero-valent iron $\left(\mathrm{Fe}^{0}\right)$, while the shell is composed of iron oxide, with the thickness of the shell layer appearing to be less than $3 \mathrm{~nm}$. These results are in agreement with our earlier ones reported for nZVI-kaolinite and nZVI-bentonite composite sorbents [12,16].

The surface of Al-nZVI was characterized using XPS. The recorded spectra (see Fig. 4) indicated a significant Fe and $\mathrm{O}$ signal with a recorded $\mathrm{Al} 2 \mathrm{p}$ peak of only limited intensity in the upper surface of the sample. The binding energy center of the Fe $2 \mathrm{p}_{3 / 2}$ peak was $710.7 \pm 0.1 \mathrm{eV}$, which is characteristic of magnetite $\left(\mathrm{Fe}_{3} \mathrm{O}_{4}\right)[17,18]$. A shoulder on the low binding energy side indicated the limited presence of metallic iron in the analysis volume. This was confirmed by curve fitting which placed the metallic Fe $2 p_{3 / 2}$ peak at a binding energy center of $706.7 \pm 0.1 \mathrm{eV}$. The $\mathrm{Al} 2 \mathrm{p}$ peaks were observed to be centered at $75.3 \pm 0.1 \mathrm{eV}$, which was similar to values previously reported for $\mathrm{Al}_{2} \mathrm{O}_{3}$. The intensity of the recorded $\mathrm{Al} 2 \mathrm{p}$ peak was very weak relative to the $\mathrm{Fe} 2 \mathrm{p}$ peaks.

The recorded $\mathrm{O} 1 \mathrm{~s}$ peak was centered at $530.9 \mathrm{eV}$. The binding energy typically reported for the $\mathrm{O} 1 \mathrm{~s}$ peak in $\mathrm{Fe}_{3} \mathrm{O}_{4}$ is

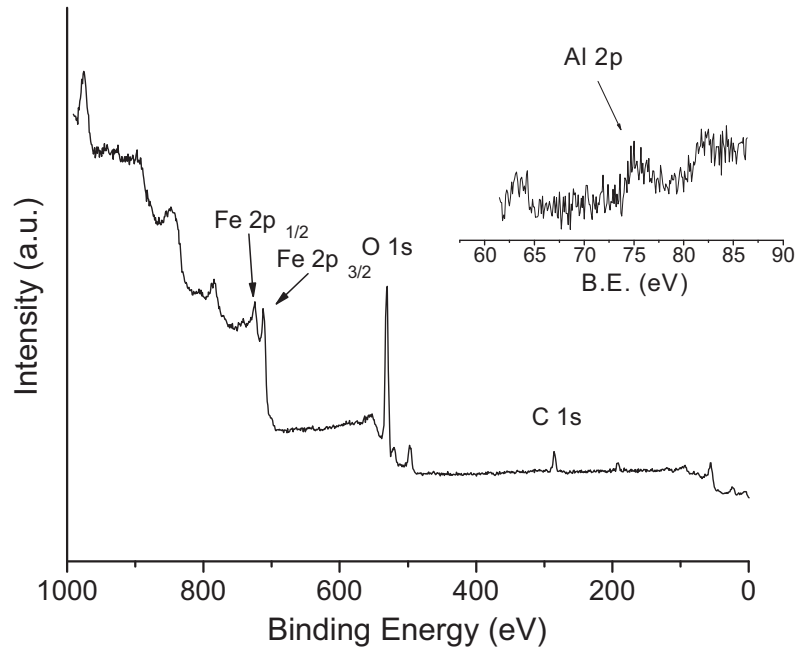

Fig. 4. XPS spectrum of Al-nZVI.

529.7-530.1 eV [18,19], while that recorded for oxygen in $\mathrm{Al}_{2} \mathrm{O}_{3}$ is widely reported to occur between 530.9 and $531.6 \mathrm{eV}$ [20-22]. Curve fitting of the recorded $\mathrm{O} 1 \mathrm{~s}$ profile identified three component peaks ascribed to magnetite $(529.9 \mathrm{eV})$, aluminum oxide $(531.3 \mathrm{eV})$ and a further peak ascribed to sorbed water at $532.5 \mathrm{eV}$.
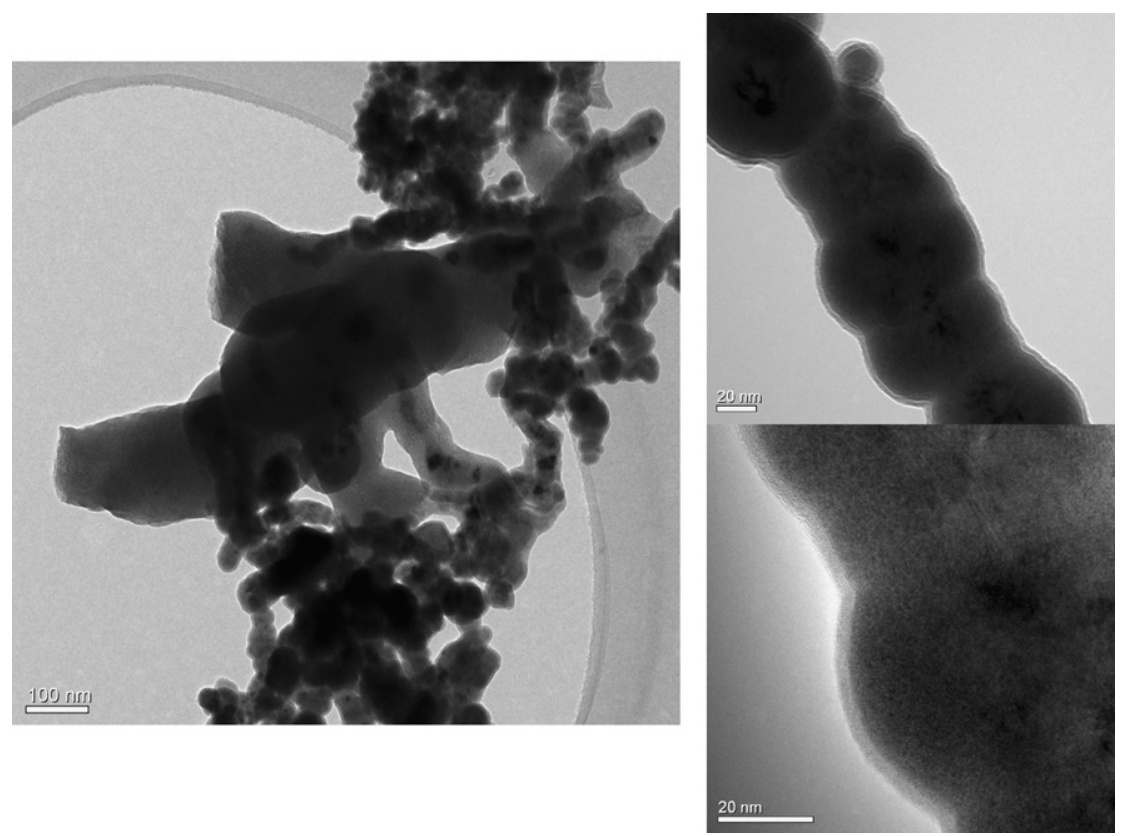

Fig. 3. HR-TEM images of Al-nZVI. 


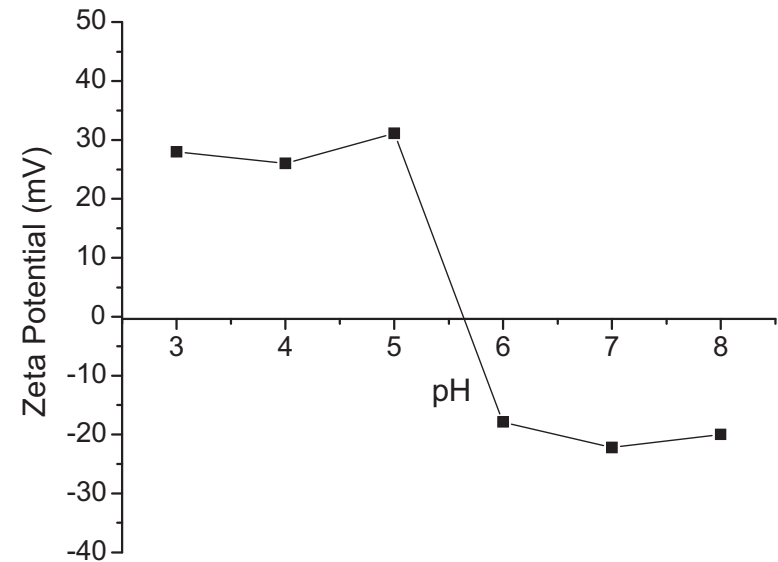

Fig. 5. Variation of zeta potential (mV) of Al-nZVI with $\mathrm{pH}$.

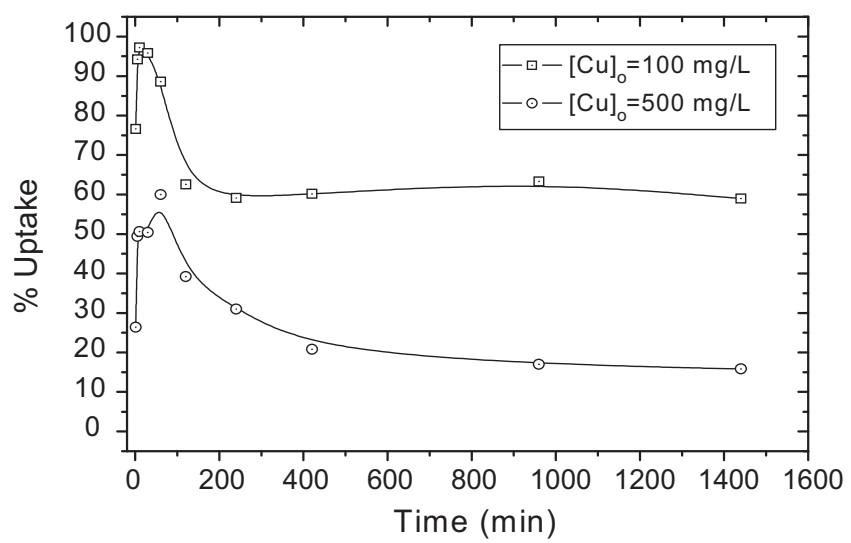

Fig. 6. Variation of the \% uptake of $\mathrm{Cu}^{2+}$ ions on $\mathrm{Al}-\mathrm{nZVI}$ with the time of contact.

The point of zero charge (pzc) of Al-nZVI was determined by zeta potential measurements to be around $\mathrm{pH}$ of 5.6 (Fig. 5). Some anomalies were observed in the measured potential possibly due to the inhomogeneous nature of the composite sorbent. This measured pzc is significantly below the pzc of nZVI which was also determined as 8.3. A lower pzc of Al-nZVI in comparison to that of pure nZVI provides a wider $\mathrm{pH}$ range within which the cationic species can be attracted to the negatively charged sorbent surface in aqueous media.

\subsection{Uptake of $\mathrm{Cu}^{2+}$ ions on $\mathrm{Al}-\mathrm{nZVI}$}

The variation in \%uptake of $\mathrm{Cu}^{2+}$ with time is shown in Fig. 6. At the initial concentration of $100.0 \mathrm{mg} / \mathrm{L}$ equilibrium is approached after $200 \mathrm{~min}$ of contact time, whereas at $500.0 \mathrm{mg} / \mathrm{L}$ concentration about $400 \mathrm{~min}$ is required to attain equilibrium. At both concentrations, the uptake is seen to increase rapidly within the first minutes. This is followed by a fast partial desorption stage that leads then to equilibrium. The kinetics of $\mathrm{Cu}^{2+}$ uptake on $\mathrm{Al}-\mathrm{nZVI}$ is slower than

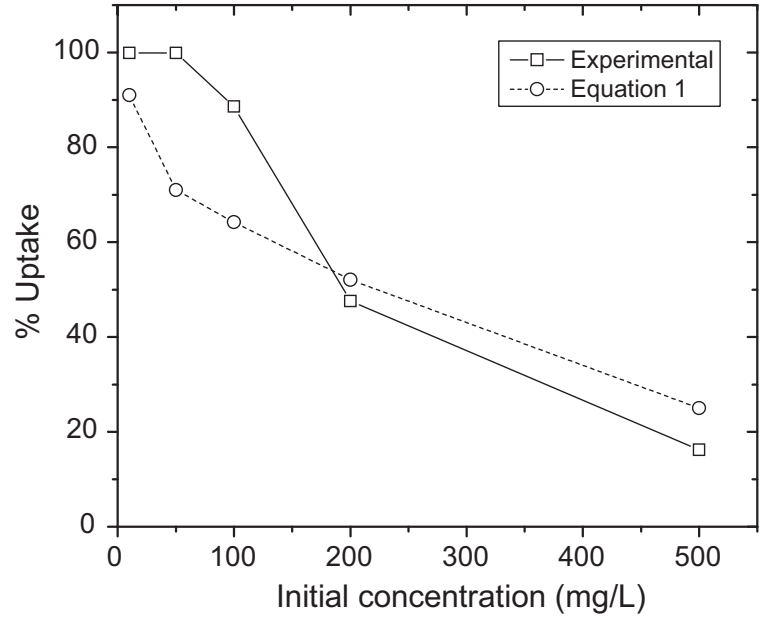

Fig. 7. \% uptake of $\mathrm{Cu}^{2+}$ ions on $\mathrm{Al}-\mathrm{nZVI}$ as a function of initial metallic ion concentration.

that observed for uptake on pure nZVI [11], which was reported to occur within several minutes of contact. This is indicative of a higher energetic barrier at the stage of surface diffusion in the case of Al-nZVI.

The results obtained from the investigations of the effect of initial concentration on the extent of removal of $\mathrm{Cu}^{2+}$ by $\mathrm{Al}-\mathrm{nZVI}$ are summarized Table 1 . The results indicate that almost a complete removal of $\mathrm{Cu}^{2+}$ ions can be achieved using Al-nZVI at the initial concentrations of 10 and $50 \mathrm{mg} / \mathrm{L}$. This is a significant result taking into consideration the small amount of the applied adsorbent dose $(0.050 \mathrm{~g}$ for $50 \mathrm{~mL}$ solution). Beyond this concentration, the uptake is seen to decrease steadily and approaches saturation within the initial concentration range of $200-500 \mathrm{mg} / \mathrm{L}$. The sorption capacity at $500 \mathrm{mg} / \mathrm{L}$ initial $\mathrm{Cu}^{2+}$ concentration of $\mathrm{Al}-\mathrm{nZVI}$ is about $1.50 \mathrm{mmol} / \mathrm{g}$ or $95.3 \mathrm{mg} / \mathrm{g}$, which is approximately five-folds that of pure alumina $(0.32 \mathrm{mmol} / \mathrm{g} ; 20.3 \mathrm{mg} / \mathrm{g})$.

For the sake of comparison, the extent of uptake of $\mathrm{Cu}^{2+}$ on pure alumina and pure nZVI are also provided in Table 1 . The superior uptake capacity of nZVI over alumina is evident from the provided results. If the $\mathrm{Al}-\mathrm{nZVI}$ composite adsorbent was behaving as an ideal mixture, then the total percentage of uptake would be predictable using the equation.

\%Uptake $=\frac{m_{\mathrm{A}}}{m_{\mathrm{A}}+m_{\mathrm{B}}}(\% \text { Uptake })_{\mathrm{A}}+\frac{m_{\mathrm{B}}}{m_{\mathrm{A}}+m_{\mathrm{B}}}(\% \text { Uptake })_{\mathrm{B}}$

where $m_{\mathrm{A}}$ and $m_{\mathrm{B}}$ are the masses of component A (nZVI) and component $B$ (alumina) in the composite. The percentage uptake is related to concentration as.

\%Uptake $=\frac{[C]_{\mathrm{o}}-[C]_{1}}{[C]_{\mathrm{o}}} \times 100 \%$

Here $[C]_{\mathrm{o}}$ is the initial concentration, and $[C]_{l}$ is the equilibrium liquid concentration of $\mathrm{Cu}^{2+}$ ions. The theoretical results obtained using Eq. (1) are compared with the experimental results in Fig. 7. It

Table 1

The amounts of $\mathrm{Cu}^{2+}$ adsorbed on Al-nZVI at different initial concentrations. The amounts of $\mathrm{Cu}^{2+}$ adsorbed on nZVI and alumina are also provided for comparison.

\begin{tabular}{|c|c|c|c|c|c|c|}
\hline \multirow[t]{2}{*}{ Initial $\mathrm{Cu}^{2+}$, conc.mg/L } & \multicolumn{2}{|l|}{$\mathrm{Al}-\mathrm{nZVI}$} & \multicolumn{2}{|l|}{ nZVI } & \multicolumn{2}{|l|}{ Alumina } \\
\hline & {$\left[\mathrm{Cu}^{2+}\right]_{\mathrm{s}}, \mathrm{mmol} / \mathrm{g}$} & \%Uptake & {$\left[\mathrm{Cu}^{2+}\right]_{\mathrm{s}}, \mathrm{mmol} / \mathrm{g}$} & \%Uptake & {$\left[\mathrm{Cu}^{2+}\right]_{\mathrm{s}}, \mathrm{mmol} / \mathrm{g}$} & \%Uptake \\
\hline 10.0 & 0.16 & $>99.9$ & 0.16 & $>99.9$ & 0.12 & 81.8 \\
\hline 50.0 & 0.78 & $>99.0$ & 0.79 & $>99.9$ & 0.32 & 41.2 \\
\hline 100.0 & 1.39 & 88.6 & 1.57 & $>99.9$ & 0.45 & 28.4 \\
\hline 200.0 & 1.49 & 47.6 & 2.84 & 90.0 & 0.44 & 14.2 \\
\hline 500.0 & 1.50 & 16.2 & 3.91 & 47.5 & 0.31 & 4.1 \\
\hline
\end{tabular}




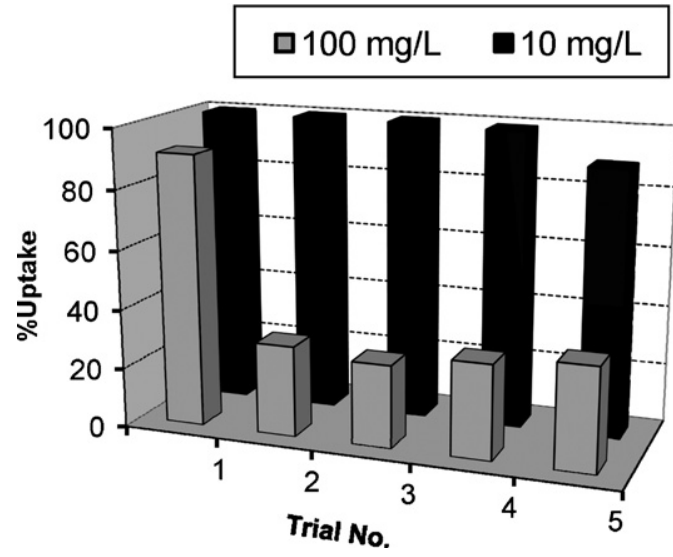

Fig. 8. Variation of the \% uptake of $\mathrm{Cu}^{2+}$ ions with the number of applications of the same Al-nZVI sample.

is seen that up to $200.0 \mathrm{mg} / \mathrm{L}$ initial concentration, the experimental uptake values are larger than those predicted by ideal behavior. This could be reflecting the superior uptake capacity of nZVI component at the lower $\mathrm{Cu}^{2+}$ concentrations. At $200.0 \mathrm{mg} / \mathrm{L}$ and $500.0 \mathrm{mg} / \mathrm{L}$ initial concentrations, the experimental values are less than predicted by Eq. (1). This suggests that the composite adsorbent undergoes deterioration in its uptake capacity at higher concentration. The reason for this is possibly the formation of a copper layer on the surface of the adsorbent as a result of the redox mechanism, in a manner that limits the accessibility to uptake sites. The mechanism of uptake is discussed in the next section.

The effect of repetitive usage of $\mathrm{Al}-\mathrm{nZVI}$ on the extent of $\mathrm{Cu}^{2+}$ uptake is given in Fig. 8. At the initial concentration of $10.0 \mathrm{mg} / \mathrm{L}$, almost a complete removal of $\mathrm{Cu}^{2+}$ ions is achievable at the successive five trials. When the initial $\mathrm{Cu}^{2+}$ concentration is raised to $100.0 \mathrm{mg} / \mathrm{L}$, a serious deterioration of the uptake capability of the

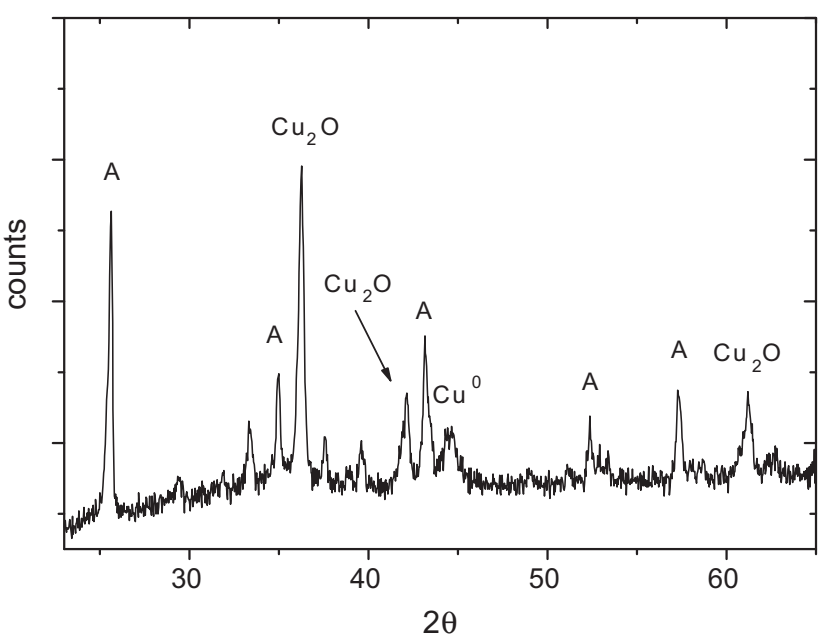

Fig. 9. XRD pattern of $\mathrm{Al}-\mathrm{nZVI}$ after uptake of $\mathrm{Cu}^{2+}$ ions at initial concentration of $500 \mathrm{mg} / \mathrm{L}$.

Al-nZVI sample was observed following the first round of mixing, and the percentage uptake decreased to about $30 \%$. Thus multiple usage of $\mathrm{Al}-\mathrm{nZVI}$ seems to be possible at low $\mathrm{Cu}^{2+}$ concentrations. It must be noted, however, that this conclusion is valid for five successive trials, and the topic may need further consideration if more trials are to be considered due to possible loss of the sorbent material as repetitive usage progresses.

The effect of $\mathrm{pH}$ on the uptake of $\mathrm{Cu}^{2+}$ was also investigated. According to the results provided in Table 2 only minimal variations occurred across the investigated $\mathrm{pH}$ range of 3.0-11.0, and nearly a complete removal of $\mathrm{Cu}^{2+}$ ions was achievable. The results are discussed within the context of the uptake mechanism presented in the following section.

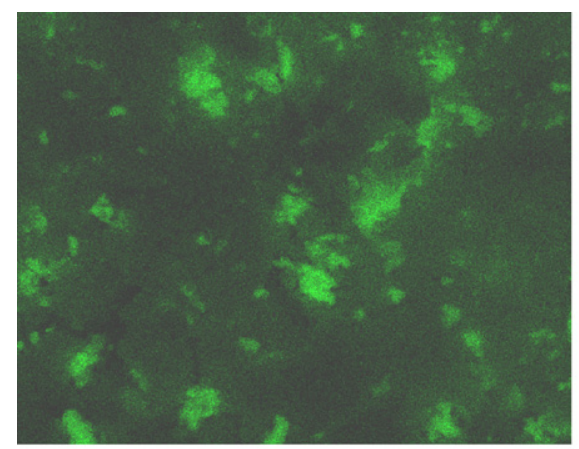

Al

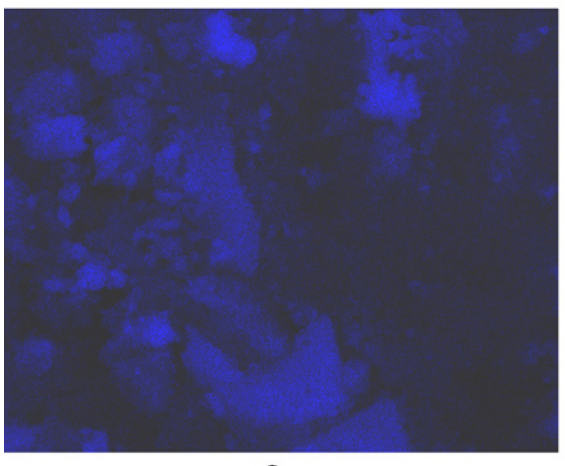

$\mathrm{Cu}$

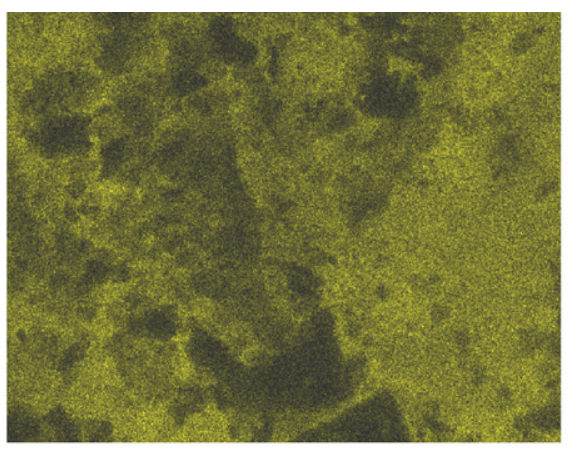

$\mathrm{Fe}$

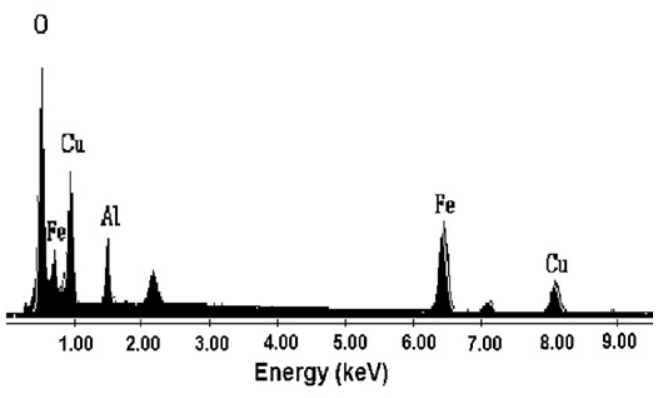

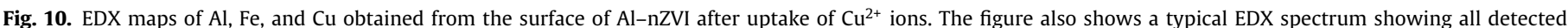
elements. 
Table 2

The effect of $\mathrm{pH}$ variation on the extent of $\mathrm{Cu}^{2+}$ retention by $\mathrm{Al}-\mathrm{nZVI}$ at initial concentration of $50.0 \mathrm{mg} / \mathrm{L}$.

\begin{tabular}{rlc}
\hline $\mathrm{pH}$ & {$[\mathrm{Cu}]_{\mathrm{l}}, \mathrm{mg} / \mathrm{L}$} & \%Uptake \\
\hline 3.0 & 1.18 & 98.8 \\
5.0 & 0.10 & 99.9 \\
7.0 & 0.04 & $>99.9$ \\
9.0 & 0.02 & $>99.9$ \\
11.0 & 0.06 & $>99.9$ \\
\hline
\end{tabular}

\subsection{Uptake mechanism}

The uptake mechanism of $\mathrm{Cu}^{2+}$ ions on pure nZVI was discussed with some detail in our earlier publication about the topic [11]. The standard reduction potential of $\mathrm{Cu}^{2+}(+0.34 \mathrm{~V}, 298 \mathrm{~K})$ is well above that of $\mathrm{Fe}^{2+}(-0.44 \mathrm{~V}, 298 \mathrm{~K})$, and hence the reduction of adsorbed $\mathrm{Cu}^{2+}$ ions by $\mathrm{Fe}^{0}$ is plausible. It was validated in our previous studies $[11,12]$ based on XPS investigations and calculation of Auger parameter that the redox process leads to the formation of cuprite, $\mathrm{Cu}_{2} \mathrm{O}$, and metallic copper, $\mathrm{Cu}^{0}$, on the surface of nZVI and $\mathrm{nZVI} /$ kaolinite. The corresponding redox reactions might be written as.

$\mathrm{Fe}^{0}+2 \mathrm{Cu}^{2+}+\mathrm{H}_{2} \mathrm{O} \rightarrow \mathrm{Fe}^{2+}+\mathrm{Cu}_{2} \mathrm{O}+2 \mathrm{H}^{+}$

$\mathrm{Fe}^{0}+\mathrm{Cu}^{2+} \rightarrow \mathrm{Fe}^{2+}+\mathrm{Cu}^{0}$

The same issue was considered also in this study. The XRD diagram obtained for $\mathrm{Al}-\mathrm{nZVI}$ after $\mathrm{Cu}^{2+}$ uptake at initial concentration of $500.0 \mathrm{mg} / \mathrm{L}$ is shown in Fig. 9. The reflections of $\mathrm{Cu}_{2} \mathrm{O}$ and $\mathrm{Cu}^{0}$ that appear in the diagram confirm our earlier findings, suggesting as well that the $\mathrm{Cu}^{2+} / \mathrm{Cu}^{+}$redox reaction occurs more intensively than that of $\mathrm{Cu}^{2+} / \mathrm{Cu}^{0}$. The operating redox mechanism might also explain the independence of the extent of uptake on the operating $\mathrm{pH}$ within the investigated range of 3.0-11.0, indicating that surface speciation of the adsorbent does not affect the aforementioned redox process.

The distribution of $\mathrm{Cu}$ on the surface of $\mathrm{Al}-\mathrm{nZVI}$ was elucidated using EDX analysis. The mapping images for $\mathrm{Fe}, \mathrm{Al}$, and $\mathrm{Cu}$ elements are shown in Fig. 10. The signals of $\mathrm{Cu}$ are not associated with those of $\mathrm{Al}$ or Fe indicating that it forms a separate phase on the adsorbent surface. The obtained intense signals of $\mathrm{Cu}$ reflect the high uptake capacity of the adsorbent. According to multiple EDX measurements, the atomic percentage of $\mathrm{Cu}$ on the surface region is around $19 \%$. Moreover, there is a high association between Cu signals and $\mathrm{O}$ signals (not shown in figure), the thing attributed to predominant formation of $\mathrm{Cu}_{2} \mathrm{O}$ compared to $\mathrm{Cu}^{0}$.

\section{Conclusions}

Partial dispersion of iron nanoparticles was achieved when the material was synthesized in the presence of alumina. The Al-nZVI composite sorbent demonstrated much more effective removal capability of $\mathrm{Cu}^{2+}$ ions compared to pure alumina. The repetitive usage of the material for the removal of $\mathrm{Cu}^{2+}$ ions at low concentrations seems to be possible. The uptake of $\mathrm{Cu}^{2+}$ ions was $\mathrm{pH}$ independent throughout the range of 3.0-11.0. This can be linked with the uptake mechanism that was verified to occur mainly via a redox route.

\section{Acknowledgements}

The authors are grateful to the Center of Materials Research at İzmir Institute of Technology for the assistance in XRD and SEM/EDX analysis. The authors thank Dr. Ingo Liberwirth at Max Planck Institute for Polymer Research for his help in HR-TEM analysis. The authors thank Dr. K.R. Hallam and Dr. T.B. Scott at the Interface Analysis Centre, University of Bristol for their help in XPS analysis.

\section{References}

[1] S. Al-Asheh, F. Banat, Adsorption of copper and zinc by oil shale, Environ. Geol 40 (2001) 693-698.

[2] Y.-H. Li, Z. Luan, X. Xiao, X. Zhou, C. Xu, D. Wu, B. Wei, Removal of $\mathrm{Cu}^{2+}$ ions from aqueous solutions by carbon nanotubes, Adsorpt. Sci. Technol. 21 (2003) 475-486.

[3] R. Rangsivek, M.R. Jekel, Removal of dissolved metals by zero-valent iron (ZVI): kinetics, equilibria, processes and implications for stormwater runoff treatment, Water Res. 39 (2005) 4153-4163.

[4] S.-F. Lim, Y.-M. Zheng, S.-W. Zou, J.P. Chen, Removal of copper by calcium alginate encapsulated magnetic sorbent, Chem. Eng. J. 152 (2009) 509-513.

[5] Y.-T. Zhou, H.-L. Nie, C.B. White, Z.-Y. He, L.-M. Zhu, Removal of $\mathrm{Cu}^{2+}$ from aqueous solution by chitosan-coated magnetic nanoparticles modified with $\alpha$-ketoglutaric acid, J. Colloid Interface Sci. 330 (2009) 29-37.

[6] M. Ozmen, K. Can, G. Arslan, A. Tor, Y. Cengeloglu, M. Ersoz, Adsorption of $\mathrm{Cu}$ (II) from aqueous solution by using modified $\mathrm{Fe}_{3} \mathrm{O}_{4}$ magnetic nanoparticles, Desalination 254 (2010) 162-169.

[7] K. Vijayaraghavan, J. Jegan, K. Palanivelu, M. Velan, Batch and column removal of copper from aqueous solution using a brown marine alga Turbinaria ornate, Chem. Eng. J. 106 (2005) 177-184.

[8] A.H. Sulaymon, B.A. Abid, J.A. Al-Najar, Removal of lead, copper, chromium, and cobalt ions onto granular activated carbon in batch and fixed-bed adsorbers, Chem. Eng. J. 155 (2009) 647-653.

[9] H.L. Zhang, Y.M. Lin, L. Wang, Biosorption of copper by calcium alginate from excess activated sludge, Environ. Technol. 30 (2009) 1461-1467.

[10] H. Harmita, K.G. Karthikeyan, X. Pan, Copper and cadmium sorption onto kraft and organosolv lignins, Bioresour. Technol. 100 (2009) 6183-6191.

[11] D. Karabelli, Ç. Uzum, T. Shahwan, A.E. Eroglu, T.B. Scott, K.R. Hallam, I. Lieberwirth, Batch removal of aqueous $\mathrm{Cu}^{2+}$ ions using nanoparticles of zero-valent iron: a study of the capacity and mechanism of uptake, Ind. Eng. Chem. Res. 47 (2008) 4758-4764.

[12] Ç. Üzüm, T. Shahwan, A.E. Eroğlu, K.R. Hallam, T.B. Scott, I. Lieberwirth, Synthesis and characterization of kaolinite-supported zero-valent iron nanoparticles and their application for the removal of aqueous $\mathrm{Cu}^{2+}$ and $\mathrm{Co}^{2+}$ ions, Appl. Clay Sci. 43 (2009) 172-181.

[13] N. Efecan, T. Shahwan, A.E. Eroğlu, I. Lieberwirth, Characterization of the uptake of aqueous $\mathrm{Ni}^{2+}$ ions on nanoparticles of zero valent iron, Desalination 249 (2009) 1048-1054.

[14] W.X. Zhang, Nanoscale iron particles for environmental remediation an overview, J. Nanopart. Res. 5 (2005) 323-332.

[15] Y.-P. Sun, X.-Q. Li, W.-X. Zhang, H.P. Wang, A method for the preparation of stable dispersion of zero-valent iron nanoparticles, Colloids Surf. A 308 (2007) 60-66.

[16] T. Shahwan, C. Uzum, A. Eroglu, I. Liberwirth, Synthesis and characterization of bentonite/iron nanoparticles and its application as adsorbent of cobalt ions, Appl. Clay Sci. 47 (2010) 257-262.

[17] T.B. Scott, G.C. Allen, P.J. Heard, M.G. Randell, Reduction of U(VI) to U(IV) on the surface of magnetite, Geochim. Cosmochim. Acta 69 (2005) 5639-5646.

[18] G.C. Allen, M.T. Curtis, A.J. Hooper, P.M. Tucker, X-ray photoelectron spectroscopy of iron-oxygen systems, J. Chem. Soc. Dalton Trans. 14 (1974) 1525-1530.

[19] B.J. Tan, K.J. Klabunde, P.M.A. Sherwood, X-ray photoelectron spectroscopy studies of solvated metal atom dispersed catalysts. Monometallic iron and bimetallic iron-cobalt particles on alumina, Chem. Mater. 2 (1990) 186-191.

[20] B.J. Tan, K.J. Klabunde, P.M.A. Sherwood, XPS studies of solvated metal atom dispersed (SMAD) catalysts. Evidence for layered cobalt-manganese particles on alumina and silica, J. Am. Chem. Soc. 113 (1991) 855-861.

[21] C.D. Wagner, D.E. Passoja, H.F. Hillery, T.G. Kinisky, H.A. Six, W.T.Jansen, J.A. Taylor, Auger and photoelectron line energy relationships in aluminum-oxygen and silicon-oxygen compounds, J. Vac. Sci. Technol. 21 (1982) 933-944.

[22] E. Paparazzo, XPS analysis of oxides, Surf. Interface Anal. 12 (1988) 115-118. 